\title{
Basic requirements for plasma sources in medicine
}

\author{
Klaus-Dieter Weltmann, Thomas von Woedtke \\ Leibniz Institute for Plasma Science and Technology (INP Greifswald) \\ Felix-Hausdorff-Str.2, D-17489 Greifswald, Germany
}

Phone: +49 (0) 3834554 310; Fax: +49 (0) 3834554301

E-mail: weltmann@inp-greifswald.de

\begin{abstract}
Plasma medicine is a new medical field with first very promising practical studies. However, basic research needs to be done to minimize risk and provide a scientific fundament for medical therapies. Therapeutic application of plasmas at or in the human body is a challenge both for medicine and plasma physics. Today, concepts of tailormade plasma sources which meet the technical requirements of medical instrumentation are still less developed. To achieve selected effects and to avoid potential risks, it is necessary to know how to control composition and densities of reactive plasma components by external operation parameters. Therefore, a profound knowledge on plasma physics and chemistry must be contributed by physical research. Therapeutic applications required cold, non-thermal plasmas operating at atmospheric pressure. These plasmas are a huge challenge for plasma diagnostics, because usually they are small scale, constricted or filamentary, and transient. Regarding the manageability in everyday medical life, atmospheric pressure plasma jets (APPJ) and dielectric barrier discharges (DBD) are of special interest for medical applications. Working in open air atmospheres, complex plasma chemistry must be expected. Considering that, a great deal of effort combining experimental investigation and modelling is necessary to provide the required knowledge on plasma sources for therapeutic applications.
\end{abstract}

\section{Introduction}

Actually, plasma medicine is emerging worldwide as an independent medical field comparable to the launch of laser technology into medicine years ago. The application of lowpressure as well as atmospheric pressure plasma sources is well established in several industrial processes. During recent years, new possibilities of plasma applications in the medical field are opened. Decontamination or sterilization of medical devices and implants is a very promising field of plasma application just as the fabrication or optimization of 
biomaterials. However, these applications which are well researched and partially transferred into practical applications already, are indirect plasma applications, i.e. plasma is used to prepare or qualify devices or materials for subsequent medical applications. The new field of plasma medicine will go far beyond this because in its main focus is the direct application of physicals plasmas at or in the human or animal body. One of the most important visions is plasma treatment of chronic wounds to enable a selective antimicrobial (antiseptic) activity without damaging the surrounding tissue, combined with a controlled stimulation of tissue regeneration. Other promising fields are tissue engineering, treatment of skin diseases, tumor treatment based on specific induction of apoptotic processes, or dental applications.

To realize these visions, a fundamental knowledge of the mechanisms of plasma interaction with living cells and tissue is essential as a scientific basis which needs an intensive interdisciplinary cooperation with life scientists and clinicians. But, there is also a huge challenge for plasma physicists because

- a detailed characterization of the plasma as a complex physical system is the basic prerequisite to understand as well as to control specific responses of complex biological systems, and

- plasma application in direct contact with living systems needs a high level of safety which has to be guaranteed above all by physical and technical means.

Therefore, therapeutic application of plasmas is not only a task for medicine; it is a challenge for plasma physics as well.

\section{Plasma sources for medical applications}

Even if from plasma physical point of view a large "tool-box" of plasma sources is available (Fig. 1), the intended use in plasma medicine limits the spectrum of useable tools. Therapeutic applications of plasmas dictate the working in open air atmospheres and thus at atmospheric pressures. Adjusted plasma sources for different applications are required, and the proposed selectivity of plasma action implies a thoughtful control of the performance parameters of the plasma sources. This regards the treatment efficiency but also the potential risks connected with the direct plasma application at or in the human body. In particular, there are three tasks to fulfil:

1. Assessment of risk factors such as gas temperature, power transfer from the plasma, UV radiation, reactive species including radicals, electromagnetic fields as well as the generation of toxic gases and its release into the adjacencies which could be dangerous for patients or therapists 
2. Characterization of special biologic effects, e.g., antimicrobial efficiency, cell manipulation, or blood coagulation, including the estimation of specific adverse or toxic side effects in the close cell and tissue environment

3. Profound understanding and knowledge of processes and physical plasma parameters in order to provide optimal tools for the achievement of specific effects as well as to avoid undesired side effects [1].

During recent years a broad spectrum of plasma sources intended for biomedical applications has been reported in the scientific literature. The long list containing plasma needle [2], atmospheric pressure plasma plume [3], floating-electrode dielectric barrier discharge (FEDBD) [4], atmospheric pressure glow discharge torch (APGD-t) [5], microhollow cathode discharge air plasma jet [6], microwave plasma torch [7], helium plasma jets [8-10], dielectric barrier discharge [11], and nanosecond plasma gun [12], is far from being comprehensive. Additionally, there is a growing number of commercially available plasma sources which are dedicated to be useful for different biomedical application by the respective providers. However, in most cases it is not completely clear which biological or medical tests are the bases for such a declaration.

For our own experimental work, up to now we have used mainly three different plasma sources:

- atmospheric pressure plasma jet (APPJ; kINPen 09, neoplas tools GmbH, Greifswald, Germany) with argon as preferred working gas [13]

- surface dielectric barrier discharge (surface DBD) working in atmospheric air [14,15]

- intermittent negative dc-corona discharge with argon as working gas (hairline plasma) [16] The APPJ kINPen 09 (Fig. 2) is the most developed and intensively tested plasma tool which has got the $\mathrm{CE}$ marking (electromagnetic compatibility), thus fulfilling the EU consumer safety, health or environmental requirements. It has been used for numerous biomedical investigations so far [1,13]. The whole system consisting of a hand-held unit for the generation of a plasma jet at atmospheric pressure, a DC power supply, and a gas supply unit, works with all rare gases (especially argon) but also with nitrogen and air and admixtures of molecular gases to the feed gas. The plasma is ignited at the tip of a centred electrode inside a capillary and blown out by the gas flow to form the plasma jet. Because of the contracted plasma resulting from this type of generation, APPJ is suitable especially for focused smallspot treatments even of small size objects also with high aspect ratios. Large-scale treatments are realizable by moving the jet over a selected area [13]. These features make them interesting for the treatment of bodily parts with complex geometries and cavities, e.g. in 
operative dentistry or dermatology. If needed, plasma jets can be arranged in arrays to adapt on special geometries [17].

Surface DBD is a useful device for indirect treatment of flat targets like material or liquid surfaces. The electrode array consisted of epoxy-glass fiber bulk material for circuit boards serving as dielectric with a high-voltage structured copper electrode arrangement on the one side and a non-structured flat copper surface served as counter electrode at ground potential on the other side (Fig. 3). DBD is performed at ambient air conditions using a pulsed sinusoidal voltage of $10 \mathrm{kV}_{\text {peak }}(20 \mathrm{kHz})$ [15]. Since the complete electrode design can be incorporated in a single component [1] it was possible to mount it by a special construction into the upper shell of a petri dish in that way that the distance between the high-voltage electrode surface and the surface of the sample in the lower shell of the petri dish can be adjusted variable. This experimental setup makes it ideal for biomedical investigations using microorganism cultures on agar surfaces or cell cultures as well as cells suspended in liquids. In contrast to volume barrier discharge systems where the target to be treated is part of the discharge configuration $[1,4,11]$, in this setup the plasma is ignited on the surface of the electrode arrangement which can be brought close to the target. Because there is neither direct plasma contact to the target nor a gas flow, all plasma effects are assumed to be indirect effects induced by radiation or diffusion of more or less stable reactive chemical species. Dependent on intended applications, other geometries and electrode arrangements are possible [14].

The hairline plasma schematically shown in Fig. 4 is a specially designed plasma source for the generation of nanosecond-pulsed cold plasma using a simple dc-power supply and is able to penetrate into small and long gaps like tooth root canals [16].

Furthermore, a broad spectrum of other plasma sources is available which can be adapted for the investigation of special biological effects or therapeutic needs [1]. However, besides all technical as well as physical details and features, decision if an atmospheric pressure plasma source may be useful for biomedical application should be made using the following 10 questions:

1. Is the clinical efficacy proved?

2. Is the absence of undesirable local or systemic side effects (mutagenic, carcinogenic, toxic effects; pains, scars, pigmentation disorders...) proved?

3. Is the medical effect reliable?

4. Is the medical effect well controllable?

5. Can a quick medical effect be realized? 
6. Is it possible to exclude the development of resistances when treating infectious diseases as well as co-treating resident flora?

7. Is it possible to exclude inhibitory effects on normal microbiological flora?

8. Is it cost-effective?

9. Is it sure that there are no alternative solutions with what it could be done easier?

10. Will the plasma treatment be accepted both by patients and physicians?

Only if at least most of these questions can be affirmed a further development up to clinical proofs is acceptable. Naturally, the main precondition to deal with these questions is to define an exact field of intended therapeutic application. The first two questions are playing a key role because plasma medical research has to guarantee the application of a Tissue Tolerable Plasma (TTP) with proved clinical efficacy but without or at most with minimal side effects whose acceptability has to be decided dependent on the intended therapeutic use [18]. For this purpose, both a comprehensive and careful physical characterisation and optimization of the plasma sources and a comprehensive characterization of biological effects is indispensable.

\section{Characterization of plasma sources - plasma physics}

With regard to medical plasma applications, the estimation of general risk factors is at least that much important to clarify minimum standards for plasma sources to allow it for direct medical applications and for comparison of different sources. From the present point of view the minimum set of global risk factors to be characterized are

- plasma temperature,

- UV radiation,

- generation of toxic gases and its release into the adjacencies which could be dangerous for patients or therapists, and

- electromagnetic fields of special frequency generated by the plasma source.

Especially from the point of practical manageability as well as with regard to the actual state of technical development, atmospheric pressure plasma jet (APPJ) is of special interest for medical applications. Therefore, using the kINPen 09, systematic characterization of global risk factors which could arise but have to be avoided during application of this tool will be demonstrated. The general aim being true for all plasma sources intended for therapeutic applications is the setting up of minimum standards which have to be matched if a plasma source is intended for further research and development up to transfer into clinical practice. 


\subsection{Temperature}

Temperature is one of the most critical factors in connection with plasma treatment of living systems. Tissue temperature should not exceed a threshold of $40^{\circ} \mathrm{C}$ in general to prevent thermal effects in the living tissue [19]. Axial temperature profiles of the plasma jet can be measured by fibre optic temperature measurement (Fig. 5).

First of all, data presented in Fig. 5 indicate plasma jet temperatures between $63^{\circ} \mathrm{C}$ and $46^{\circ} \mathrm{C}$, dependent on power input and axial distance from the capillary nozzle of the plasma source. But, secondly, it shows also the variable length of the visible plasma jet dependent on power input indicated by circular marks. At this tip of the visible plasma jet, temperatures have been measured more or less constant around $48^{\circ} \mathrm{C}$. On principle, these plasma jet temperatures are very close to biological intolerance. However, plasma-caused surface or tissue heating, respectively, is not only dependent on gas or plasma temperature but also a function of contact time. So it could be demonstrated that fast moving atmospheric microwave plasma with a temperature of about $3000^{\circ} \mathrm{C}$ can be used for decontamination of heat sensitive hollow packaging materials which are melting above $70{ }^{\circ} \mathrm{C}[20]$. If the APPJ will be used for wound antiseptics or skin treatment, respectively, it will not be done as a local spot treatment but by moving the plasma jet over the surface to be treated [21]. Therefore, following adequate application techniques, adverse effects of local tissue heating can be excluded as far as possible. On the other hand, these data demonstrate the necessity of measuring axial temperature profiles of the jet to decide if during practical applications the distance between jet nozzle and target surface will be critical. Because of the relatively constant temperature at the tip of the visible plasma jet independent on its complete length, the visible tip of the plasma jet can be used to adjust a general treatment distance. Using such adjustment, effective antimicrobial effects can be realized as it was demonstrated repeatedly [13, 21, 22].

For further minimization of the temperature problem, alternative working modes can be used like alternating plasma-on/plasma-off phases, e.g. with constant plasma-on but variable plasma-off time intervals. Such working parameter control leads to further reduction of net energy input and, subsequently, reduced heating of the plasma to realize plasma temperatures $<40^{\circ} \mathrm{C}$ over the whole length of the jet (Fig. 5) [13].

\subsection{UV radiation}

Because the influence of UV radiation on the skin is another potential risk of atmospheric pressure plasma treatment, a careful characterization of optical emission spectra of plasma sources which are intended to use for plasma medical applications is necessary. Especially 
UV-C around $254 \mathrm{~nm}$ is well known for its direct impact in DNA which is one possible component of antimicrobial plasma efficiency but also a safety hazard in the case of plasma treatment of mammalian cells and living tissue. For plasma jets under atmospheric conditions with argon as working gas, the presence of UV-C radiation and its intensity depends strongly on the working conditions. Whereas with a rf-driven plasma jet with $7 \mathrm{~mm}$ nozzle diameter and argon gas flow of up to $20 \mathrm{slm}$ distinct UV-C radiation can be measured [23], for the kINPen 09 designated for biomedical applications emission in the UV-A (320-400 nm) and UV-B range (280-320 nm) was found, only [13].

Besides a permanent exposition of parts of human skin to solar UV-A and UV-B radiation, it is used in phototherapy and photochemotherapy to treat skin diseases as psoriasis and atopic dermatitis. Therefore, UV impact on skin is well investigated particularly in dermatology because excess UV exposure causes detrimental effects on skin. To exclude this, according to guidelines of the International Commission on Non-Ionizing Radiation Protection (ICNIRP), non-therapeutic and non-elective ultraviolet radiant exposure of the skin in the spectral region $180-400 \mathrm{~nm}$ should not exceed $30 \mathrm{~J} / \mathrm{m}^{2}$ or $3 \mathrm{~mJ} / \mathrm{cm}^{2}$, respectively. This value should be applied for the most sensitive, non-pathologic, skin phototype (known as "melano-compromised") [24].

To estimate the UV risk of the kINPen, irradiance in the 260-360 nm UV range of the plasma jet was measured along the plasma jet at different axial distances and with different input power (Fig. 6). At minimal distance of $5 \mathrm{~mm}$ and maximum input power of $6 \mathrm{~W}$, maximum irradiance of about $5 \mathrm{~mW} / \mathrm{cm}^{2}$ was measured. With increasing distance from the capillary outlet, drastic reduction of irradiance was detected reaching values between 1 and $2 \mathrm{~mW} / \mathrm{cm}^{2}$. Under these conditions, a local spot treatment over several seconds will be possible without exceeding the ICNIRP exposure limit of $3 \mathrm{~mJ} / \mathrm{cm}^{2}$. As mentioned already, practical application of the APPJ will be realized by moving the plasma jet over the wound area, e.g. there are very short contact times at one and the same point. Therefore, with the APPJ demonstrated here and considering the substantially higher UV irradiance used for phototherapeutic purposes, UV caused problematic side effects of the plasma jet can be avoided in principle. However, it has to be noted that all exposure limits and threshold values discussed above are related to a more or less intact and uninjured skin. For open wounds the situation may be very different because in this case the UV protective skin barrier is impaired and the tissue is directly exposed to the UV irradiation. Therefore, UV threshold doses for plasma application for wound healing have to be estimated separately using biological test models. 


\subsection{Toxic gas formation}

Besides UV and heat radiation, plasma sources provide a mixture of charged and non-charged reactive species, above all reactive oxygen species (ROS) and reactive nitrogen species (RNS). Besides its key role in several biological effects, reactions of these species with each other or with surrounding air, respectively, can also induce the production of toxic gases which are emitted into the environment and could harm patients as well as doctors during therapeutic plasma applications. Most important toxic gases potentially generated by atmospheric pressure plasmas are ozone and nitrous gases as nitrogen monoxide (NO) and nitrogen dioxide $\left(\mathrm{NO}_{2}\right)$. Ozone is an air pollutant with harmful effects on the human and animal respiratory systems. Odour threshold of ozone is at $0.02 \mathrm{ppm}$ or $40 \mu \mathrm{g} / \mathrm{m}^{3}$ air. In the past, of $0.1 \mathrm{ppm}$ or $200 \mu \mathrm{g} / \mathrm{m}^{3}$ was defined as maximum allowable concentration (so-called MAK value). Due to classification as a potential carcinogen (EG category 3: substances which, because of possible carcinogenic effects, are cause for concern), such a MAK value is no longer specified. According to EU directives (2002/3/EG) for long-term expositions, usually as daily eight hour time averages, there is no health risk at concentrations up to 0.055 $\mathrm{ppm}$ or $110 \mu \mathrm{g} / \mathrm{m}^{3}$. To test the ozone emission, measurements using Dräger tubes have been done at different radial distances around a plasma jet driven with different power input (Fig. 7).

Maximum concentrations between 0.10 and $0.13 \mathrm{ppm}$ have been measured in the close proximity of the plasma jet, only. More afar, ozone gas concentration did not exceed a concentration of $0.10 \mathrm{ppm}$. Consequently, the permissible exposure limit will be exceeded, but because of short term therapeutic plasma applications not for extended time periods. Nevertheless, designing clinical practicable plasma based medical device, a surrounding gas exhaustion technique should be planned [13].

NO is a toxic gas which is well known to be generated by atmospheric pressure plasma sources. However, it is oxidized instantly to $\mathrm{NO}_{2}$ in the presence of oxygen or other oxidants. Therefore, in an atmospheric air environment, $\mathrm{NO}_{2}$ is the gas component which could be emitted by plasma sources into the environment. It is a prominent air pollutant, too, which has a characteristic sharp, biting odor which is also toxic by inhalation. Its odour threshold is at 0.4-5 ppm, MAK value was set at $5 \mathrm{ppm}$ or $9 \mathrm{mg} / \mathrm{m}^{3}$, but like ozone it is classified as a possible carcinogen and, therefore, a current MAK value is not specified. However, using Dräger tubes for nitrogen dioxide detection, no measurable concentrations of this gas were found around the operating plasma jet [13]. 


\subsection{Electromagnetic fields}

Additional potential risk factors are electromagnetic fields of special frequency generated by the plasma source, which could induce electrolysis in the tissue or stimulate nerve or muscle cells [19]. However, that should not be a problem with the kINPen 09 which have passed a technical certification as CE-certification (electromagnetic compatibility), thus fulfilling the standards for electrical safety in humans. Such kind of certification should be the preferred way to use plasma sources for biomedical applications.

Summarizing all, these four technical characterizations - plasma temperature, UV radiation, generation/emission of toxic gases and electromagnetic compatibility - should be realized with all plasma sources which are designed for biomedical applications independent on their intended use because these parameters could give a basic overview about the quality as well as the practical applicability of the plasma source.

Additional parameters like power transfer or transfer of different reactive species from the plasma to the target have to be investigated in close correlation with biological effects of the respective plasma source with the aim of much more detailed characterization of special safety hazards on the one side and potential therapeutic issues on the other.

\section{Characterization of plasma sources - cell-based test models}

Characterization of biologic plasma effects has to be a multi-step program starting with investigations of plasma-liquid interactions and has to include a broad spectrum of in vitro tests with cells as well as cell and tissue cultures up to isolated tissues or organs to be proved finally with animal experiments and clinical trials [25].

\subsection{Plasma effects on liquids}

Under in vivo conditions, living cells and tissue as well as microorganisms e.g. on wounds are surrounded by a liquid environment necessary for living tissue and supporting survival and proliferation of bacteria. Consequently, plasma effects under these conditions should be at least partially mediated by this vital environment. Recent studies have demonstrated that biological plasma effects like inactivation of bacteria suspended in aqueous liquids are accompanied as well as supported by changes of the liquid environment [15]. Decrease of $\mathrm{pH}$ and generation of species like nitrite, nitrate or hydrogen peroxide could be measured as a result of atmospheric pressure plasma treatment. Generation of such species cannot only support bacteria inactivation in liquids, but could also play important roles in other biological 
processes e.g. associated with wound healing. Therefore, plasma-treatment of water and subsequent measurement of $\mathrm{pH}$ as well as nitrite, nitrate and hydrogen peroxide can give some basic information about potential biological plasma effects.

\subsection{Plasma effects on microorganisms}

To get further basic assessment of biological plasma effects, estimation of antimicrobial activity is a widely used practice. In contrast to the characterization of plasma sources for sterilization or bio-decontamination of materials or devices, where highly resistant bacteria spores mostly dried on surfaces are used as test microorganisms, characterization of plasma sources for plasma medical applications needs preferably vegetative microorganisms under in vivo like, i.e. above all under humid or liquid conditions. For this purpose, both microorganisms suspended in aqueous liquids or grown on half rigid media (agar) are used $[15,21]$. E. coli is a test microorganisms often used for basic plasma source characterization $[13,16]$. However, with special microorganisms like wound pathogens or dermatophytes, characterization of the antibacterial plasma effectivity can also give information about possibilities of special plasma applications e.g. for wound antiseptics or treatment of skin infections (Fig. 8) [21,22].

\subsection{Plasma effects on in-vitro cultivated mammalian cells}

The main characteristic of plasma sources for use in medical therapy is its direct application on or in the human body. Therefore, plasma effects on mammalian cells are of basic interest. In vitro tests to characterize plasma-cell interactions should include characterization of basic cellular parameters like morphology, viability or proliferation, characterization of special cellular responses like influence on DNA or cellular proteins, and estimation of complex cellular responses like tissue regeneration or selective microorganism inactivation without influence on the surrounding tissue. In recent years several studies about influences of atmospheric pressure plasmas on different cell types in vitro have been published [8, 10, 2639].

For our own experiments, so far we are using mainly human spontaneously transformed keratinocytes (HaCaT) [40]. If these cells suspended in nutrient medium are seeded in cell culture dishes they proliferate and grow as a two-dimensional (2D) culture forming an adherent cell monolayer. To investigate plasma effects on cells to characterize basic as well as special cellular responses, both plasma treatment of cells suspended in cell culture media and subsequent cell cultivation in cell-culture dishes or cultivation of cells in cell-culture dishes 
and plasma treatment of adherent two-dimensional monolayer cell cultures are used as basic experimental setups. Both setups have special advantages dependent on cell responses that are wanted to investigate as well as on the plasma source that should be characterized.

One of the basic parameters of plasma-cell interaction is the cell viability after plasma treatment. Using two-dimensional adherent cell cultures, cell viability can be estimated in the simplest case by microscopy or by cell-staining techniques as it is demonstrated in Fig. 9. In the first case, live and death cells are differentiated by morphologic characteristics. In the second case, mostly fluorescent dyes are used which interact in a specific manner with cellular components of vital or death cells. Such two-dimensional adherent cell cultures are especially useful to investigate effects on already grown cell cultures mostly being in the stationary phase. If extended plasmas, e.g. generated by a surface barrier discharge are used, homogeneity of plasma treatment as well as localized plasma effects can be visualized using such cell cultures.

However, because these cell cultures are covered with a thin layer of cell culture medium it is not so easy to characterize plasma sources working with a gas flow like atmospheric pressure plasma jets (APPJ), because it leads to displacement of medium and subsequent cell death because of drying [41]. In such a case, treatment of cells in suspension is advantageous. Because of the gas flow, stirring of cell suspensions is given resulting in a complete treatment of the bulk liquid and thus of all cells contained. Moreover, investigation using cell suspended in aqueous liquids can be very easy correlated with results of plasma-liquid interactions as described above. As it is demonstrated in Fig. 10, with this experimental setup the extent of cell growth and proliferation, respectively, dependent on plasma treatment parameters is estimated. Suspended cells are seeded in cell culture dishes following plasma treatment. After a reasonable time (at least $2 \mathrm{~d}$ ), the number of cells grown is estimated in relation to an untreated control. The fewer cells survived the plasma treatment in suspension, the fewer cells can proliferate. In the experiment demonstrated in Fig. 10, the number of cells decreased dramatically dependent on argon APPJ treatment time. This becomes particularly clear with the results $4 \mathrm{~d}$ after plasma treatment. However, even after 20 min APPJ treatment, surviving cells can proliferate which is indicated by an increasing cell number from day 2 to day 4 . Such basic tests of cell viability after plasma treatment have to be the starting point for further detailed characterizations of biological plasma effects. Both cells in suspension and adherent two-dimensional cell cultures can be used to detect the intracellular occurrence of reactive oxygen species (ROS) as an indicator for oxidative stress. For this purpose, special chemical probes are used which can diffuse membranes of vital cells and are oxidized by ROS to 
fluorescent chemical compounds. It was demonstrated that APPJ treated keratinocytes (HaCaT) showed high levels of intracellular ROS [41]. Because it is generally assumed that ROS are playing a key role in biological plasma effects, these investigations will need much more attention in further research and the characterization of intracellular ROS should be one basic parameter of characterization of biological plasma effects.

A further important field of plasma effects on cells is the examination of interactions with biological macromolecules. First of all, interactions with DNA are of key interest especially in terms of safety and estimation of potential risks. To obtain basic information on DNA defects resulting from plasma treatments single cell electrophoresis (Comet assay) is used [42]. First preliminary results show significant influences on DNA (mostly single strand breaks) after APPJ treatment of suspended human keratinocytes (HaCaT), but there was also found a tendency of repair within 4 to $24 \mathrm{~h}$ after plasma treatment (unpublished data). Because of its importance, these investigations have to be forced using additional techniques as micronucleus assay, flow cytometry, and fluorescence microscopy to get more detailed information about basic plasma influences on genetic code of cells.

Summarizing this, together with basic technical parameters (see chapter 3), basic biological characteristics of plasma activity in vitro like change of water composition, cell growth and viability using suspended cells and/or adherent two-dimensional cell cultures, intracellular ROS generation as well as interactions with DNA are necessary to estimate the potential of plasma sources for therapeutic applications in relation to the risk-benefit balance. Which special cell-based in vitro models as well as biochemical and cell biological techniques should be used has to be decided in further experiments. Finally, a representative spectrum of basic in vitro techniques which is accepted to be mandatory in the plasma-medical community will make possible reproducible as well comparable plasma source characterizations.

\section{Applied plasma medicine - standardized medical devices for animal tests, clinical trials and medical applications}

The introduction of physical plasma into clinical practice is not only a big challenge for interdisciplinary research at the interface between plasma physics and life sciences. Particularly because of several contributions in public media worldwide, there are growing expectations especially of patients but also of physicians which are waiting for innovative tools and techniques to address unmet clinical need. Despite the field of plasma medicine is very new and mainly in an experimental state of development yet, there are first signs of its 
huge economical potential. Here, plasma-medical research community has to take responsibility to answer these legitimate public expectations by responsible and reliable research but without inspiring the hope of short-term and easy to get solutions of all medical problems including healthcare costs.

To take account of this ambivalent situation, a responsible use of plasma sources which are designated for biomedical applications is needed. To put life scientists as well as physicians in a position to decide if a given plasma source is really useful for medical applications or biological experiments, a meaningful and mandatory spectrum of indicators has to be compiled to enable a basic estimation of the potential of a plasma source.

Up to now there are no generally accepted criteria according to which atmospheric-pressure plasma sources can be assessed as to their suitability for medical applications so far. Consequently, definitions of physical-technical as well as biological criteria need to be established. As a first step to help to evaluate plasma sources for biomedical applications according to risk analysis, the minimum set of criteria has to include temperature, UV radiation, emission of gaseous products and electromagnetic compatibility in relation to geometry and operative parameters.

Characterization of biological plasma effects including specific effects on human cells as well as microorganisms in vitro has to be set up both in consideration of risk analysis and estimation of potential applications. The minimum set of biologic criteria should include influence on aqueous media ( $\mathrm{pH}$ changes, generation of stable chemical species), antimicrobial efficacy under in vivo-like conditions (wet or humid environment), influence on viability of mammalian cells, intracellular occurrence of ROS and influence on intracellular DNA. Other criteria can be added optionally to characterize special biologic effects related to special applications or risks, respectively.

A necessary next step is to make such a set of basic plasma physical as well as biological performance parameters mandatory and to transfer it into legal rules and standards including a risk analysis considering different field of potential application.

Plasma medicine is a new field with huge chances for medicine, with significant research potential. It is broad enough to promote co-operations and is an opportunity not only for medical therapy but for plasma technology , too. 


\section{Acknowledgements}

This work was partly supported by the Federal Ministry of Education and Research (BMBF), FKZ 13N 9779 (Campus PlasmaMed). The authors would like to thank all team members and cooperation partners for their motivation and commitment.

\section{References}

[1] K.-D. Weltmann, E. Kindel, Th. von Woedtke, M. Hähnel, M. Stieber, R. Brandenburg, Pure Appl. Chem. 82, 1223 (2010)

[2] E. Stoffels, A.J. Flikweert, W.W. Stoffels, Plasma Sources Sci. Technol. 11, 383 (2002)

[3] M. Laroussi, X. Lu, Appl. Phys. Lett. 87, 113902 (2005)

[4] G. Fridman, M. Peddinghaus, H. Ayan, A. Fridman, M. Balasubramanian, A. Gutsol, A. Brooks, G. Friedman, Plasma Chem. Plasma Process 26, 425 (2006)

[5] S. Coulombe, V. Léveilleé, S. Yonson, R.L. Leask, Pure Appl. Chem. 78, 1147 (2006)

[6] J.F. Kolb, A.-A. H. Mohamed, R.O. Price, R.J. Swanson, A. Bowman, R.L. Chiavarini, M. Stacey, K.H. Schoenbach, Appl. Phys. Lett. 92, 241501 (2008)

[7] T. Shimizu, B. Steffes, R. Pompl, F. Jamitzky, W. Bunk, K. Ramrath, M. Georgi, W. Stolz, H.-U. Schmidt, T. Urayama, S. Fujii, G.E. Morfill, Plasma Process. Polym. 5, 577 (2008)

[8] A. Shashurin, M. Keidar, S. Bronnikov, R.A. Jurjus, M.A. Stepp, Appl. Phys. Lett. 93, $181501(2008)$

[9] S. Rupf, A. Lehmann, M. Hannig, B. Schäfer, A. Schubert, U. Feldmann, A. Schindler, J. Med. Microbiol. 59, 206 (2010)

[10] H.J. Lee, C.H. Shon, Y.S. Kim, S. Kim, G.C. Kim, M.G. Kong, New J. Phys. 11, 115026 (2009)

[11] M. Kuchenbecker, N. Bibinov, A. Kaemling, D. Wandke, P. Awakowicz, W. Viöl, J. Phys. D: Appl. Phys. 42, 045212 (2009)

[12] E. Robert, E. Barbosa, S. Dozias, M. Vandamme, C. Cachoncinlle, R. Viladrosa, J.M. Pouvesle, Plasma Process. Polym. 6, 795 (2009)

[13] K.-D. Weltmann, E. Kindel, R. Brandenburg, C. Meyer, R. Bussiahn, Ch. Wilke, Th. Von Woedtke, Contrib. Plasma Phys. 49, 631 (2009)

[14] M. Hähnel, Th. von Woedtke, K.-D. Weltmann, Plasma Process. Polym. 7, 244 (2010) 
[15] K. Oehmigen, M. Hähnel, R. Brandenburg, Ch. Wilke, K.-D. Weltmann, Plasma Process. Polym. 7, 250 (2010)

[16] R. Bussiahn, R. Brandenburg, T. Gerling, E. Kindel, H. Lange, N. Lembke, K.-D. Weltmann, Th. Von Woedtke, T. Kocher, Appl. Phys. Lett. 96, 143701 (2010)

[17] K.-D. Weltmann, R. Brandenburg, Th. von Woedtke, J. Ehlbeck, R. Foest, M. Stieber, E. Kindel, J. Phys. D: Appl. Phys. 41, 194008 (2008)

[18] A. Kramer, N.-O. Hübner, O. Assadian, H. Below, C. Bender, H. Benkhai, B. Bröker, A. Ekkernkamp, W. Eisenbeiß, A. Hammann, B. Hartmann, C.-D. Heidecke, P. Hinz, I. Koban, S. Koche, T. Kocher, J. Lademann, O. Lademann, M.M. Lerch, S. Maier, R. Matthes, G. Müller, I. Partecke, C. Rändler, K.-D. Weltmann, M. Zygmunt, GMS Krankenhaushyg. Interdiszip. 4, Doc10 (2009)

[19] M. Zenker, GMS Krankenhaushyg. Interdiszip. 3, Doc15 (2008)

[20] J. Ehlbeck, R. Brandenburg, Th. Von Woedtke, U. Krohmann, M. Stieber, K.-D. Weltmann, GMS Krankenhaushyg. Interdiszip. 3, Doc14 (2008)

[21] G. Daeschlein G, Th. von Woedtke, E. Kindel, R. Brandenburg, K.-D. Weltmann, M. Jünger, Plasma Process. Polym. 7, 227 (2010)

[22] G. Daeschlein, S. Scholz, Th. von Woedtke, M. Niggemeier, E. Kindel, R. Brandenburg, K.-D. Weltmann, M. Jünger, IEEE Trans. Plasma Sci., DOI: 10.1109/TPS.2010.2063441 (2010)

[23] R. Brandenburg, J. Ehlbeck, M. Stieber, Th. von Woedtke, J. Zeymer, O. Schlüter, K.D. Weltmann, Contrib. Plasma Phys. 47, 72 (2007)

[24] ICNIRP - International Commission on Non-Ionizing Radiation Protection, Health Phys. 87, 171 (2004)

[25] K.-D. Weltmann, Th. von Woedtke, IEEE Trans. Plasma Sci., submitted (2010)

[26] E. Stoffels, I.E Kieft, R.E.J. Sladek, J. Phys. D: Appl. Phys. 36, 2908 (2003)

[27] E. Stoffels, I.E. Kieft, R.E.J. Sladek, L.J.M. van den Bedem, E.P. van der Laan, M. Steinbuch, Plasma Sources Sci. Technol. 15, S169 (2006)

[28] E. Stoffels, Y. Sakiyama, D.B. Graves, IEEE Trans. Plasma Sci. 36, 1441 (2008)

[29] E. Stoffels, A.J.M. Roks, L.E. Deelman, Plasma Process. Polym. 5, 599 (2008)

[30] I.E. Kieft, J.L.V. Broers, V. Caubet-Hilloutou, D.W. Slaaf, F.C.S. Ramaekers, E. Stoffels, Bioelectromagnetics 25, 362 (2004)

[31] I.E. Kieft, D. Darios, A.J.M. Roks, E. Stoffels, IEEE Trans. Plasma Sci. 33, 771 (2005)

[32] I.E. Kieft, M. Kurdi, E. Stoffels, IEEE Trans. Plasma Sci. 34, 1331 (2006) 
[33] Y. Yonson, S. Coulombe, V. Léveillé, R.L. Leask, J. Phys. D: Appl. Phys. 39, 3508 (2006)

[34] G. Fridman, A. Shereshevsky, M.M. Jost, A.D. Brooks, A. Fridman, A. Gutsol, V. Vasilets, G. Friedman, Plasma Chem. Plasma Process. 27, 163 (2007)

[35] X.-M. Shi, G.-J. Zhang, Y.-K. Yuan, Y. Ma, G.M. Xu, Y. Yang, Plasma Process. Polym. 5, 482 (2008)

[36] M. Leduc, D. Guay, R.L. Leask, S. Coulombe, New J. Phys. 11, 115021 (2009)

[37] D. Dobrynin, G. Fridman, G. Friedman, A. Fridman, New J. Phys. 11, 115020 (2009)

[38] A. Shashurin, M.A. Stepp, T.S. Hawley, S. Pal-Sosh, L. Brieda, S. Bronnikov, R.A. Jurjus, M. Keidar, Plasma Process. Polym. 7, 294 (2010)

[39] S. Kalghatgi, G. Friedman, A. Fridman, A. Morss Clyne, Ann. Biomed. Eng. 38, 748 (2010)

[40] P. Boukamp, R.T. Petrussevska, D. Breitkreutz, J. Hornung, A. Markham, N.E. Fusenig, J. Cell Biol. 106, 761 (1988)

[41] K. Wende, K. Landsberg, U. Lindequist, K.-D. Weltmann, Th. von Woedtke, IEEE Trans. Plasma Sci. 38, 2479 (2010)

[42] E. Rojas, M.C. Lopez, M. Valverde, J. Chromatography B 722, 225 (1999) 


\section{Figure captions}

Fig. 1. Atmospheric pressure plasmas - "tool-box"

Fig. 2. Atmospheric-pressure plasma jet (kINPen 09, neoplas tools $\mathrm{GmbH}$,) for experimental biomedical applications (left: CE approved device; right: schematic set-up) $[1,13]$

Fig. 3. Surface dielectric barrier discharge arrangement [15]

Fig. 4. Left: schematic of the hairline plasma setup; right: hairline plasma filament in a prepared root canal of a human tooth [16].

Fig. 5. Gas temperature of the kINPen 09 in the continuous (left) and the burst working mode (right) at an argon gas flow rate of $5 \mathrm{slm}$ dependent on input power and axial distance [13]

Fig. 6.: Irradiance $(260-360 \mathrm{~nm})$ of the kINPen 09 dependent on input power and axial distance from the plasma jet nozzle [13].

Fig. 7.: Ozone concentration measured by Dräger tubes at different radial distances around the kINPen 09

Fig. 8. Results of APPJ treatment of wound-relevant pathogens on agar plates ( $\mathrm{n}=20$ each), treatment area $55 \mathrm{~cm}^{2}$, treatment time $6 \mathrm{~min}$; RF - decimal reduction factor (log) [21]

Fig. 9. Adherent human keratinocyte $(\mathrm{HaCaT})$ culture after 20 min treatment by a surface DBD in atmospheric air. Left: By phase contrast microscopy live (center of the picture) and dead cells (along the edge of the picture) are distinguishable by its different morphology. Right: Using the propidium iodide staining technique, brighter colored region in the centre of the cell culture dish indicates death cells.

Fig. 10. Number of human keratinocytes (HaCaT) 2 and $4 \mathrm{~d}$ following argon atmospheric pressure plasma jet treatment of cell suspensions and subsequent cultivation in cell culture dishes 


\section{Figures}

\begin{tabular}{|c|c|c|}
\multicolumn{2}{|c|}{ Non-Thermal (NT) Plasmas } & Thermal Plasmas \\
\hline "Cold" Non-Thermal & $\begin{array}{c}\text { Translational } \\
\text { Plasmas }\end{array}$ & $($ "Hot NT") Plasmas \\
\hline$T_{i} \approx T_{g} \approx 300 \ldots 400 \mathrm{~K}$ & $\mathrm{~T}_{\mathrm{i}}<<\mathrm{T}_{\mathrm{e}} \leq 10^{4} \ldots 10^{5} \mathrm{~K}$ & $\mathrm{~T}_{\mathrm{i}} \approx \mathrm{T}_{\mathrm{g}} \approx \mathrm{T}_{\mathrm{e}}$ \\
$\mathrm{T}_{\mathrm{i}}<<\mathrm{T}_{\mathrm{e}}<10^{5} \mathrm{~K}(10 \mathrm{eV})$ & $\mathrm{T}_{\mathrm{i}} \approx \mathrm{T}_{\mathrm{g}} \leq 410^{3} \mathrm{~K}$ & $\mathrm{~T}_{\mathrm{x}}<510^{3} \ldots 10^{4} \mathrm{~K}$ \\
\hline
\end{tabular}

[1] Barrier discharges

\section{[2] Coronas}

[3] Microplasmas-Arrays

[4] Plasma jets
[5] Gliding Arc

[8] Arc
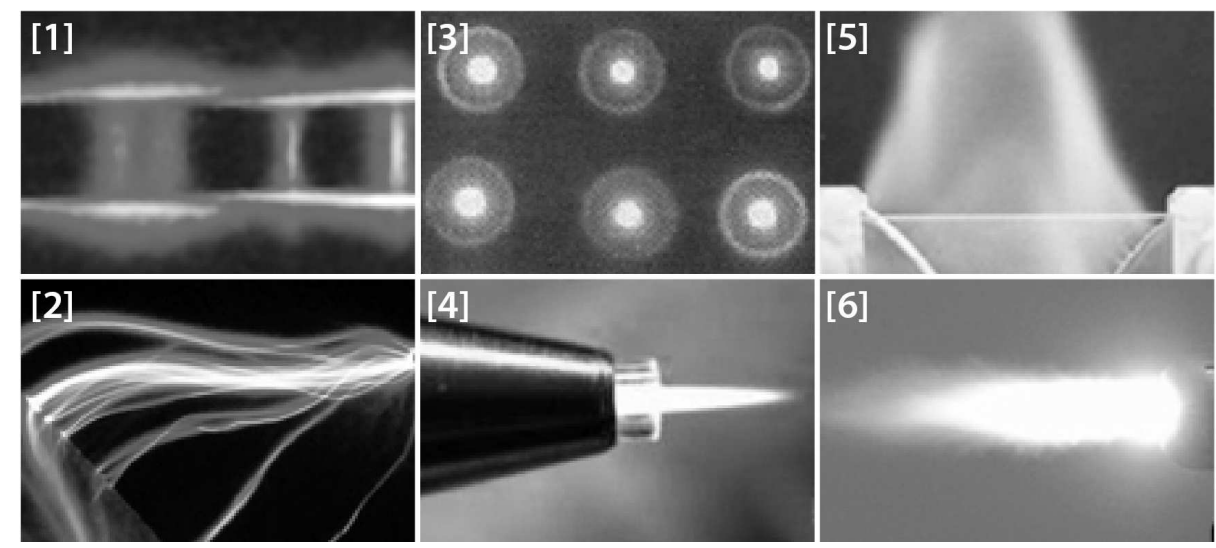

[7]

Figure 1 

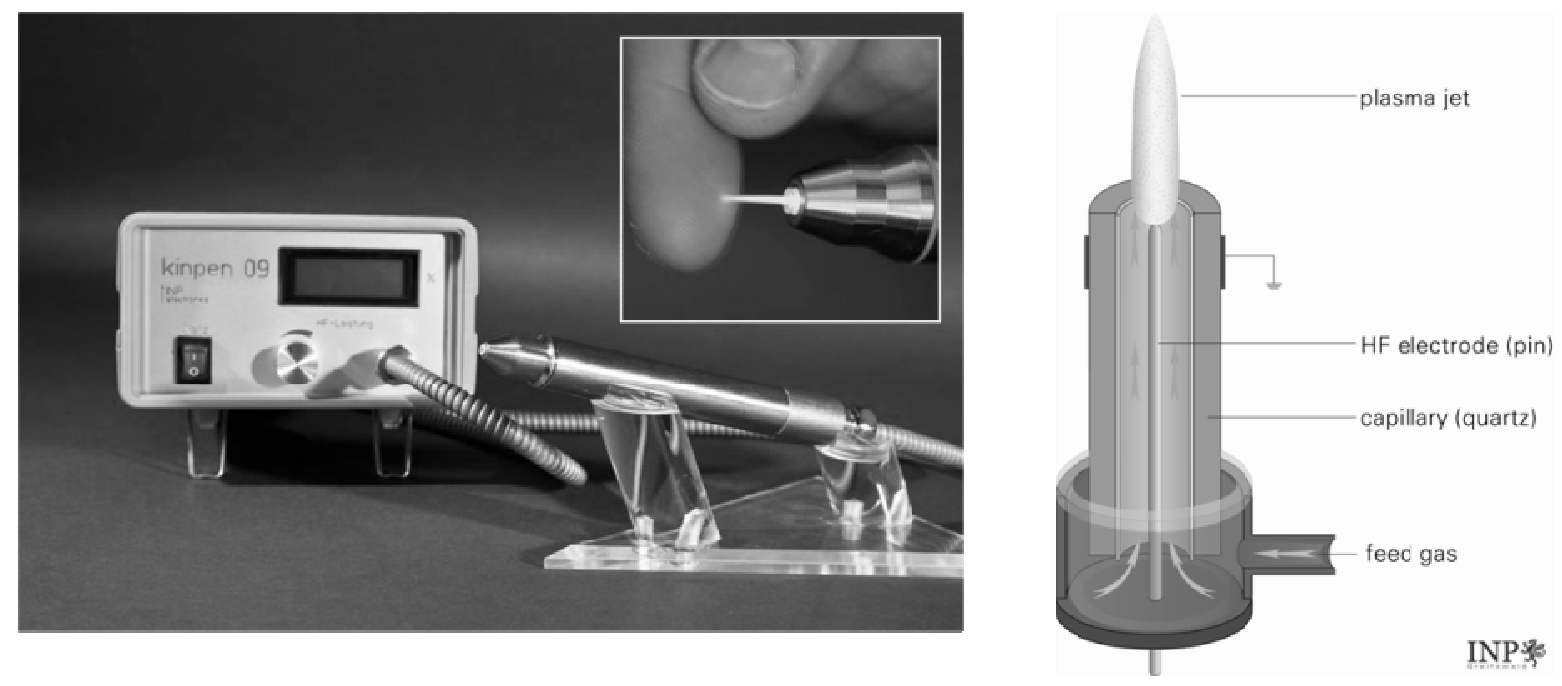

Figure 2 


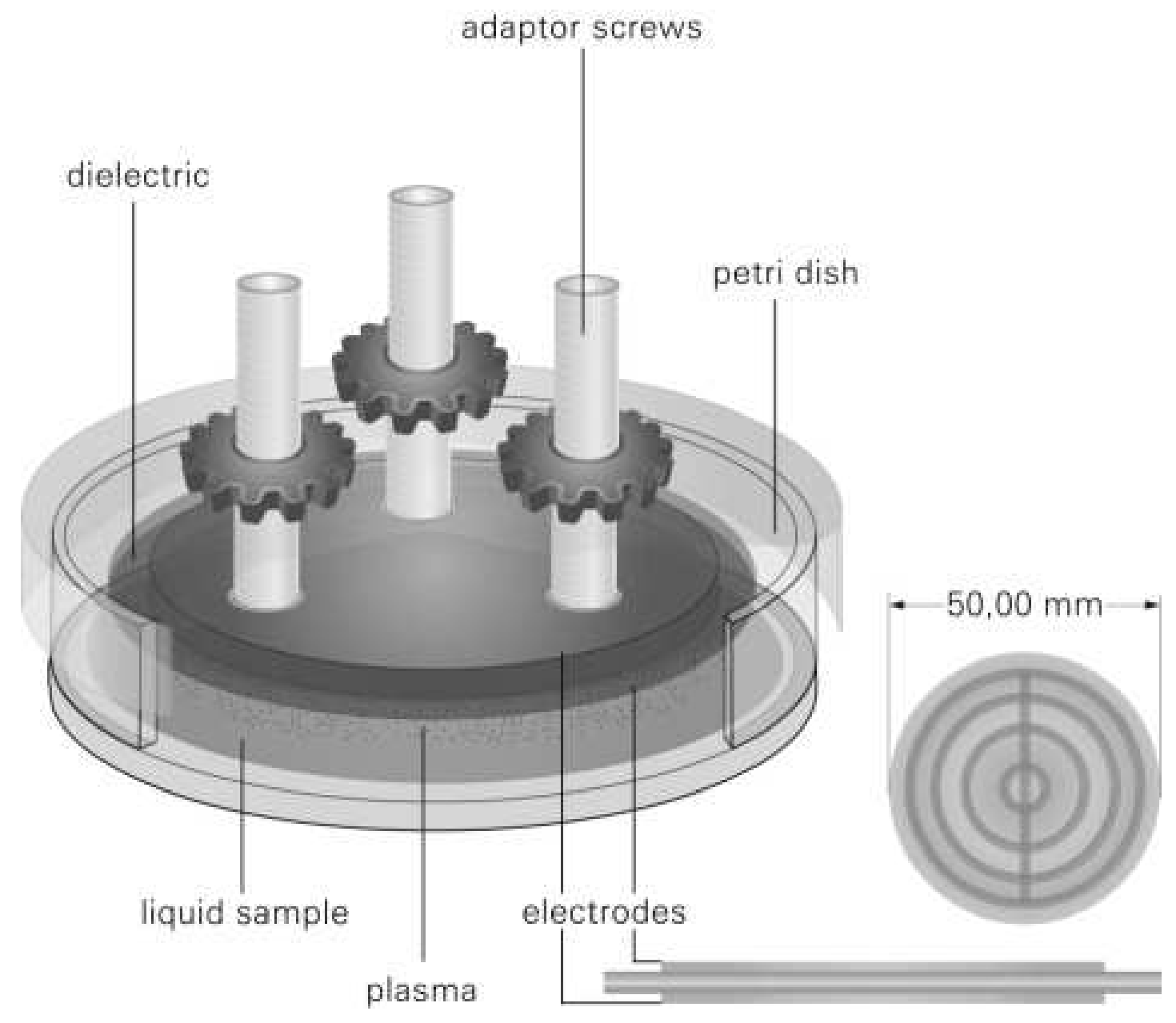

Figure 3 

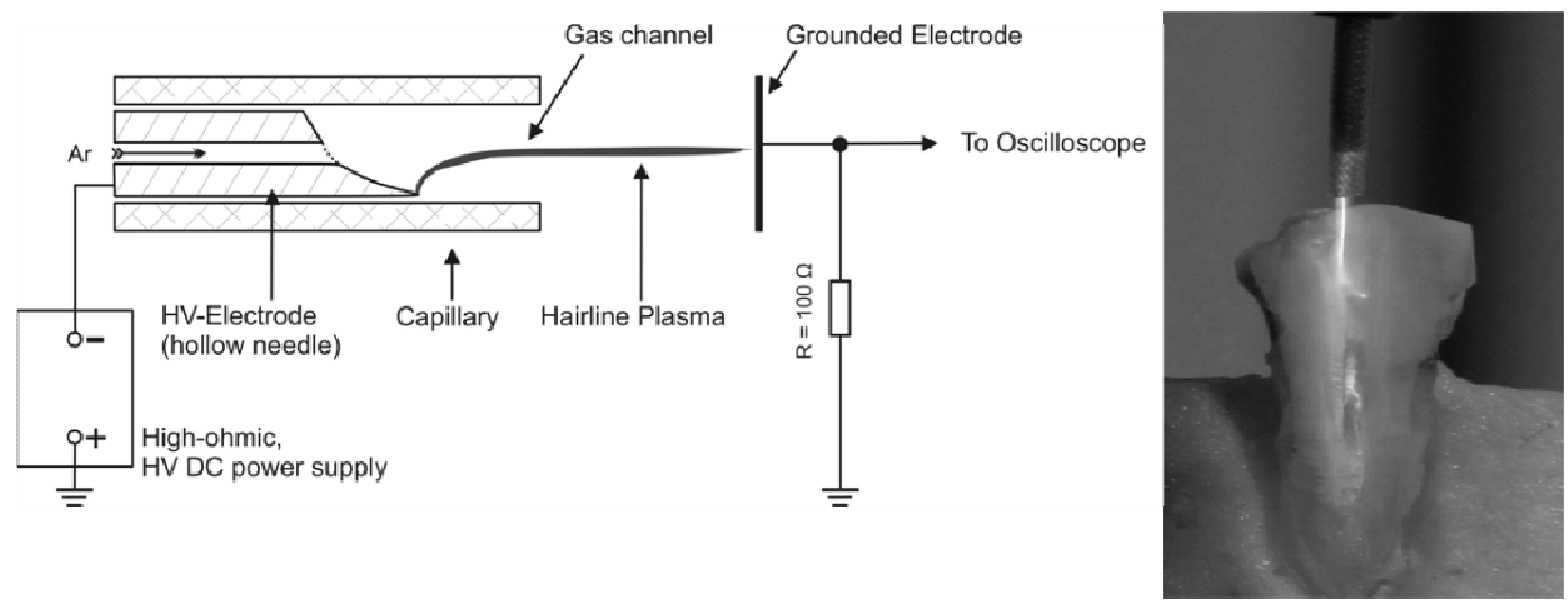

Figure 4 

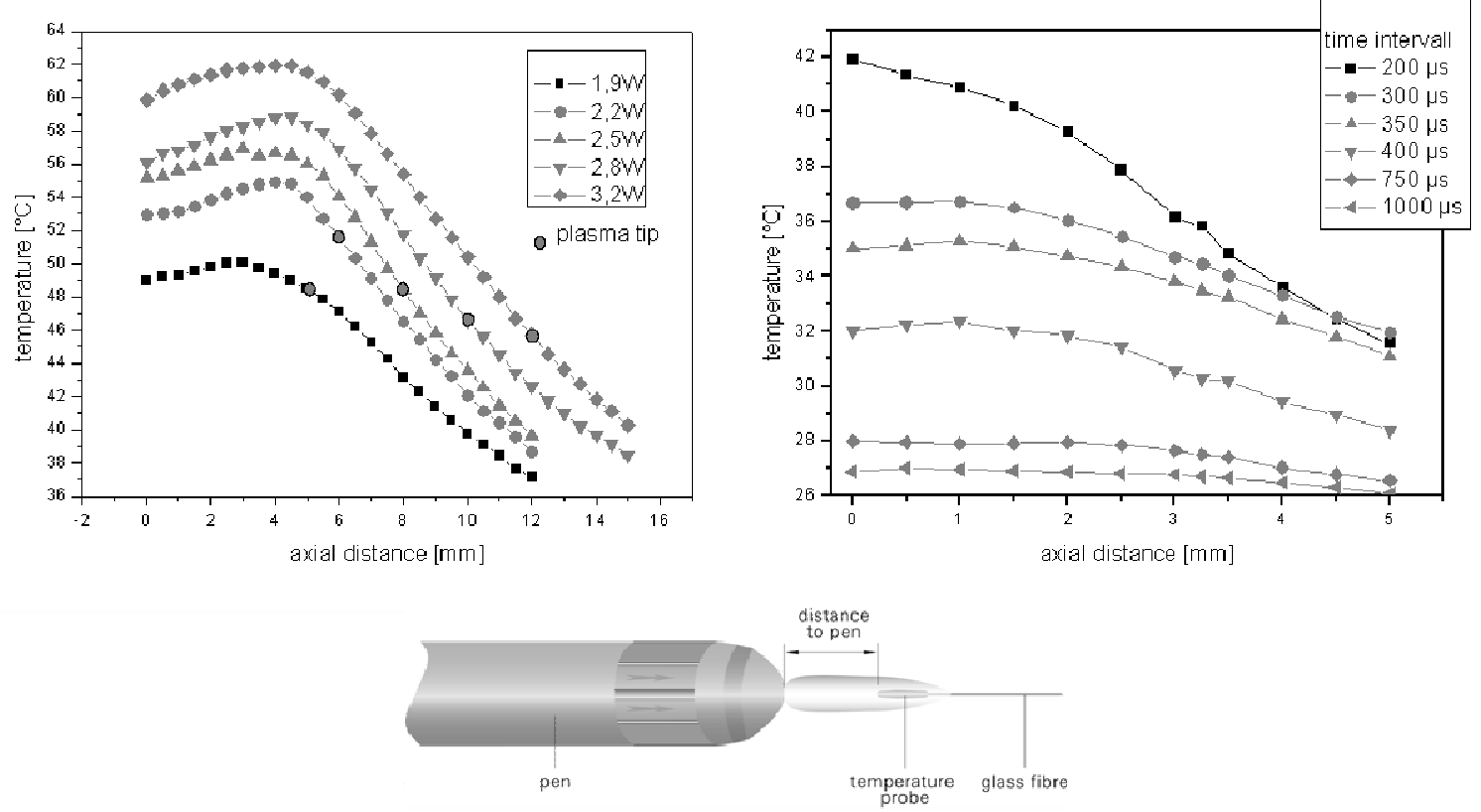

Figure 5 


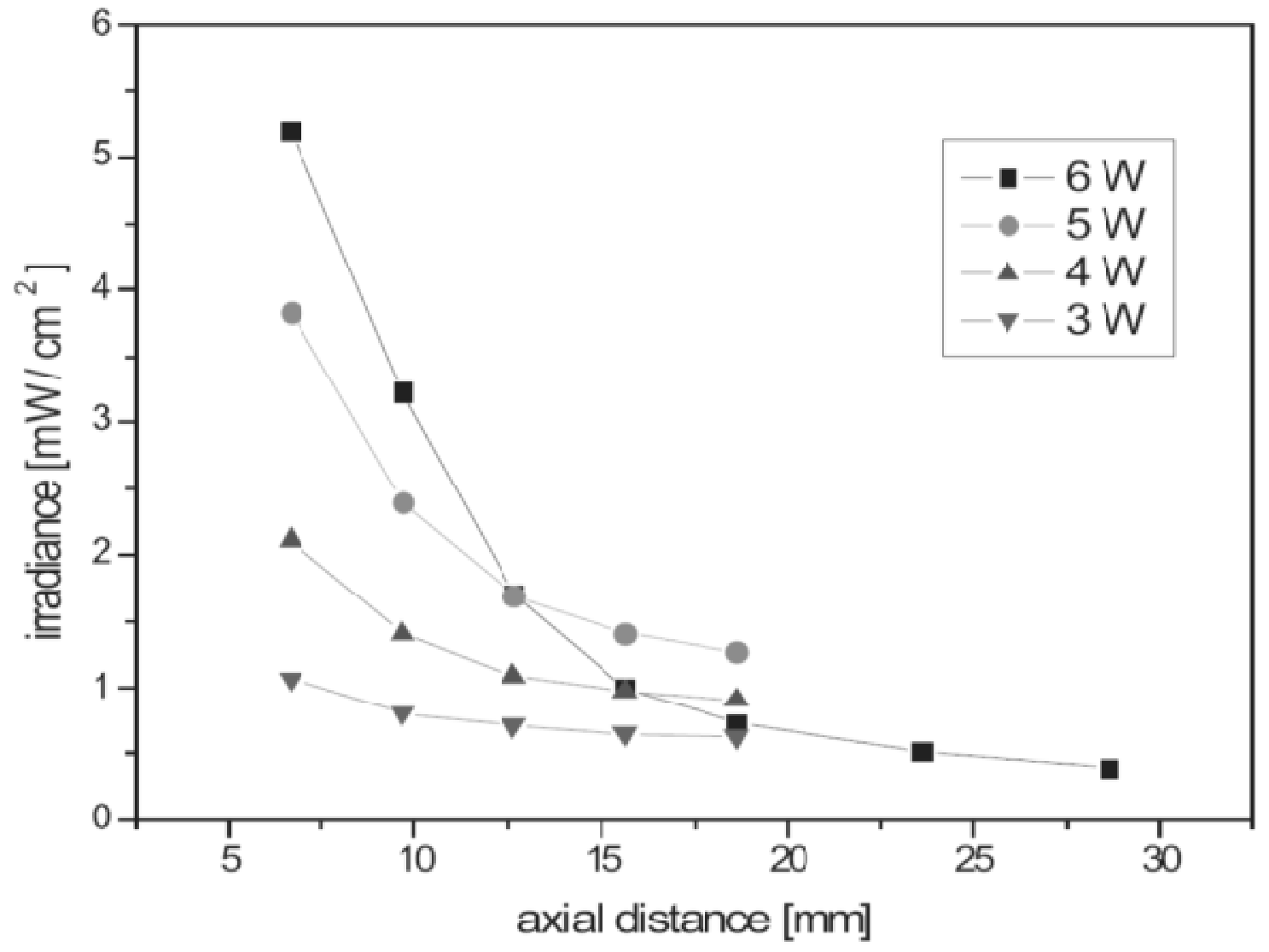

Figure 6 


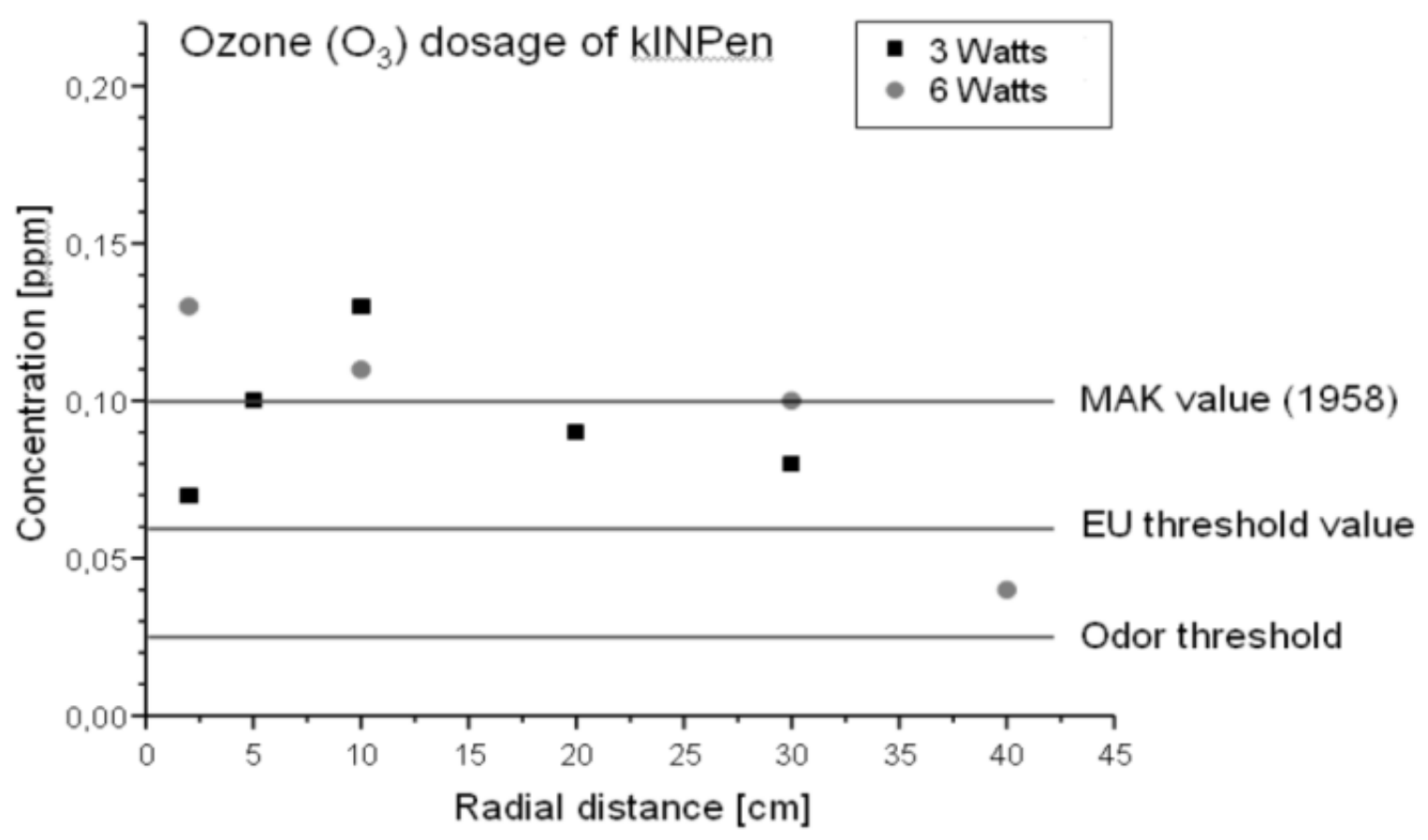

Figure 7 


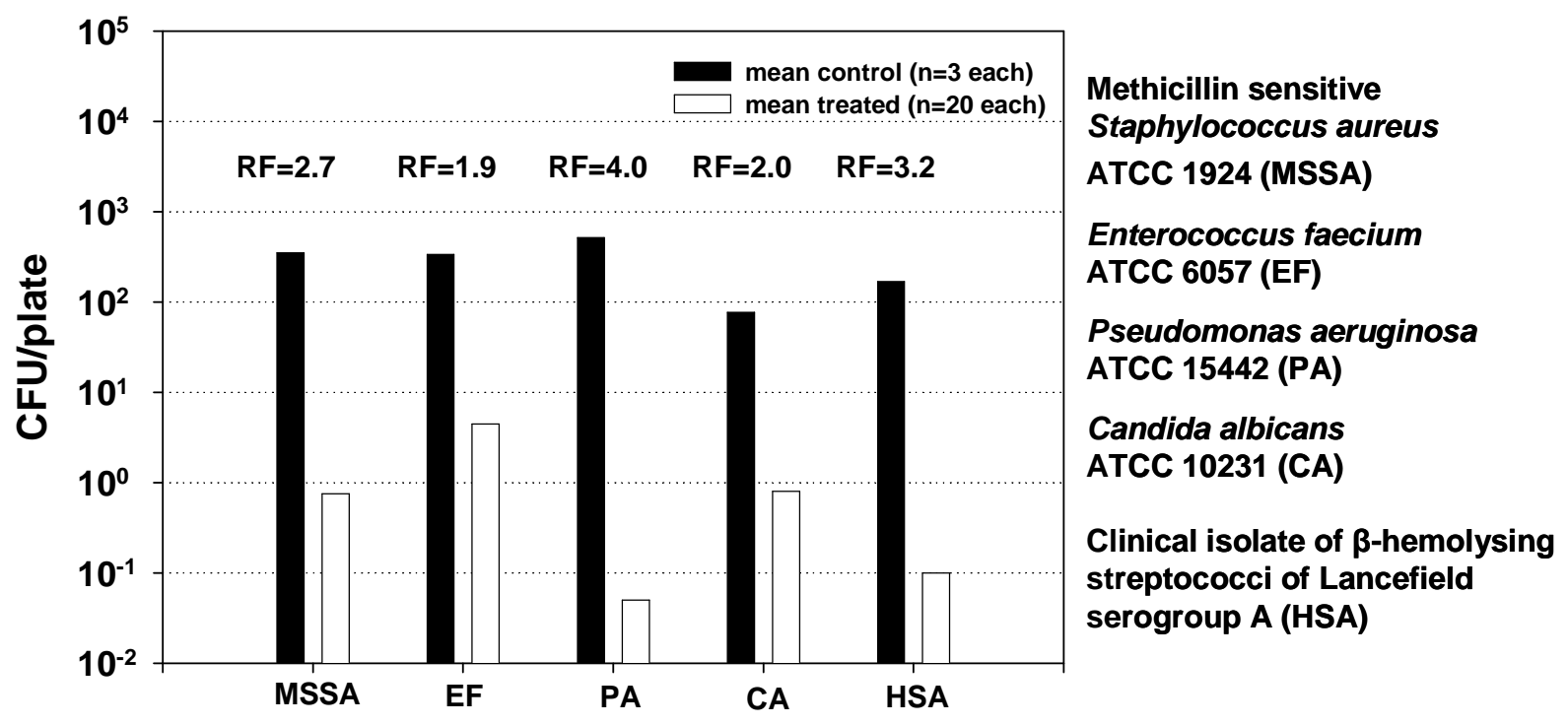

Figure 8 

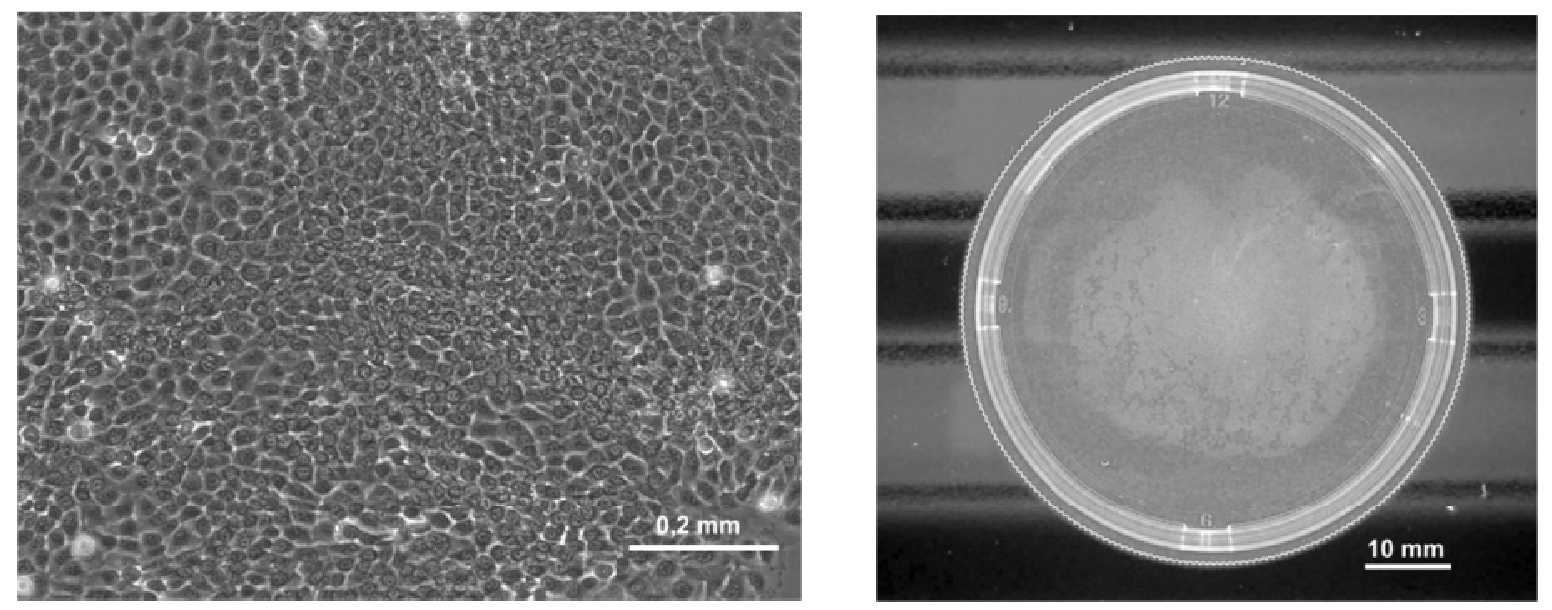

Figure 9 


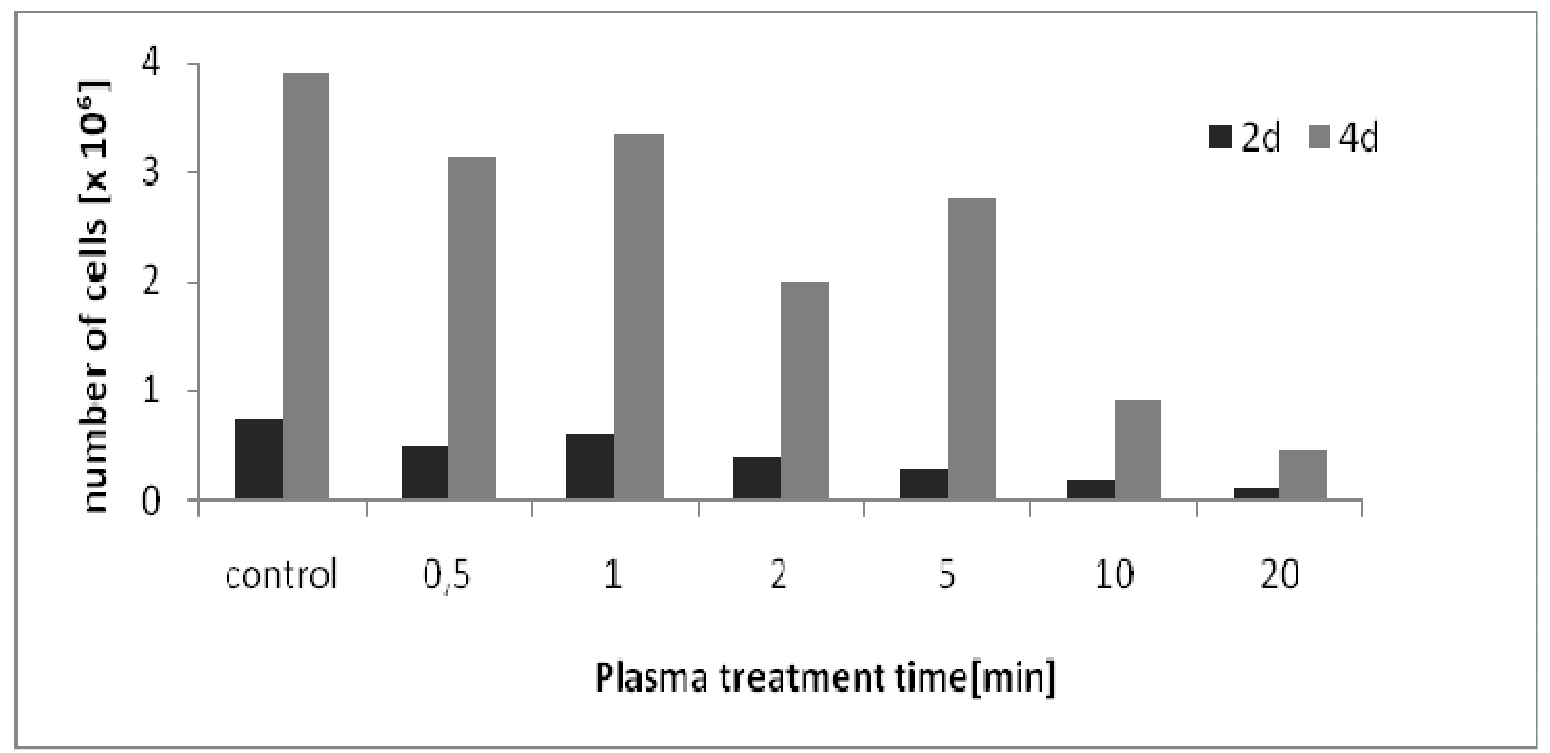

Figure 10 